\title{
The Difficulties in Translating Culture-Specific Expressions from Arabic into English
}

\author{
Ala'Eddin Banikalef* Jabr Abu Naser \\ School of English Language and Literature, Jadara, University, Postal Code 21110, Irbid, Jordan
}

\begin{abstract}
This paper examines the problems faced by undergraduate students in Jordan majoring in translation when translating culture-specific expressions from the Arabic language into the English language. To attain this aim, 11 B.A translation students were given twenty cultural expressions to translate them from Arabic into English. These expressions were taken from volume two of the Jordanian Arabic novel "Mudun al-milh" (Cities of Salt) by Dr. A Munif. The findings show that the participants encounter various types of problems when translating these expressions. These problems are frequently related to; 1 . unsuccessful attempts to attain the equivalent in the English language, and 2. inadequate knowledge in translation techniques and translation strategies. This study concludes with some recommendations, including providing at least two courses that deal with cultural differences, cultural awareness, and cultural knowledge, particularly in the academic programs that qualify translators.
\end{abstract}

Keywords: Mudun al-milh, difficulties, cultural specific expressions, Arabic-English translation

DOI: $10.7176 / \mathrm{JEP} / 10-9-09$

Publication date:March $31^{\text {st }} 2019$

\section{Introduction}

Translation plays an essential role in enabling the smooth transmission of ideas across national boundaries. It also helps in bridging the gaps between the different cultures and nations (Bahaa-eddin 2011). Some scholars such as Khammyseh \& Karak (2015) defined translation as a process of transferring ideas from one language into another. This process must express all the meaning prosperities that occur in the source language (SL) to appear in the target language. Shunnaq (2012,p. 22) believes that good translator "has to bear in mind the fact that he should exchange ideas and messages not merely words."

Moreover, translation could be defined as an attempt to provide equivalence between the source language (SL) and the target language (TL) texts (Panou 2013). Hence, the search for absolute equivalence in interlingual translation is a far-fetched aim. Belloc, (1959:85) states, "there are, properly speaking, no identical equivalents". Therefore, translators resort to a sort of equivalence which can achieve the utmost approximation or the closest possible equivalent between the source language text (SLT) and the target language text (TLT). In doing so, this means a possibility of loss and gain in meaning in most of the translations as a result of either over-translation or under-translation.

Despite the fact that many attempts have been carried out to identify the notion of equivalence, the dimensions of equivalence i. e. 'semantic VS. communicative', 'formal VS. functional' and 'Cognitive VS. affective' have not been well defined. However, it is important to keep in mind that some translation practitioners and linguists managed to be very specific in their definitions of the translation process regarding the notion of equivalence but, in fact, they were not able to distinguish between 'meaning' and 'message' and therefore, the transference of the human verbal translation cannot be fully achieved.

This study focuses on the functional equivalence (FE), which is concerned with the common cultural lexical items and it requires the use of culture-free lexical items and sometimes-new specific terms. Therefore, the (FE) neutralizes or generalizes the (SL) word and sometimes adds a particular meaning (Sholihin 2018).

\subsection{Statement of the Problem}

Many unexplored areas in the field of translation have not been tackled, especially, those areas related to the notion of equivalence in all its aspects (types) (Almubark et al. 2014). For instance, most of the culture-bound expressions, idioms and proverbs should be translated functionally, but some translators resort to semantic translation (literal translation). The reason for this might be attributed to the translator's lack of knowledge in both languages in general and in the significance of the functional equivalence in particular. In doing so, the translator might distort the message instead of conveying the precise intended meaning of the message. To prove this assumption, let us consider the following Arabic proverbs:

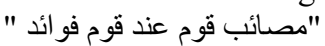

If this proverb is translated literally into English, then the image would be distorted and probably it will be something like:

"Nation's troubles are benefits to other nations". While there is a quite similar proverb in English used to indicate the same image: "One man's meat is another man's poison". The Arabic proverb ( فرخ البط عوام) ilso a good example which shows that 'literal translation' for such a proverb looks non-sensual (e.g, the duckling is a 
good-swimmer). However, its functional equivalent in English may be "like father like son".

In all cases, when cultural differences exist between the two languages, it is very hard to reach a successful transfer, if not impossible. In the same line of thought, cultural and idiomatic expressions used in literary, religious, social, and media texts constitute a main challenging area in translation, particularly when the translator belongs to a totally different culture from the writer's. Still, there are problems which must be examined, such as the challenges that appear due to a lack of understanding of particular cultural expressions between Arabic and English languages which occur because of the cultural variations. Therefore, this paper aims to explore the semantic problems that Jadara University students in Jordan encounter in translating particular culture-specific expressions from the Arabic language to the English language, and the reasons that cause these problems.

\subsection{Research Questions}

This paper aims to answer the following research questions:

1. What types of semantic problems do undergraduate students who study English Translation at Jadara University in Jordan face when translating specific cultural expressions from Arabic language into the English language?

2. What are the reasons that cause these problems?

\subsection{Significance of the Study}

To the best knowledge of the researchers, there are few researchers that have semantically studied the translation of cultural expressions in the Arab world especially Jordan. Much of the research to date has been done where most of the attention has been on specific language constructs like idioms, proverbs and collocations. Thus, this study tries to fill what appears to be a gap in translation literature. The findings of this paper will help students in translation departments and may provide them with additional suggestions when they come across such cultural expressions.

\section{Review of Related Literature}

Empirical evidence has revealed that researchers have different perspectives to the non-equivalence issue. For example, Kohil (2009) examined the problems of finding an equivalent in translating English idiomatic expressions into Arabic. In other words, she tried to understand how student's linguistic competence affects their translation performance. Twenty-five students in the English Department of the Mentouri University of Costantine were chosen randomly to complete a written translation test. The findings displayed that the errors made by the participants are more than their correct answers. They also revealed that participants face difficulties when translating idiomatic phrasal verbs from English into Arabic. The primary reasons of the participants, ' difficulties are related to their limited linguistic competence.

Khammyseh (2015), likewise, examined the problems that face M.A translation students in translating particular Islamic expressions in religious occasions from Arabic language into English language. The findings showed that there are some difficulties that face M.A translation students in translating some Islamic expressions used by Jordanians in the religious occasions. These difficulties were mainly related to the differences between both languages styles and the lack of equivalences in the target language (English). The researchers concluded that the reasons that cause these problems were the lack of experience in the culture of the target language and the lack of knowledge in both languages structures.

Moreover, Alrishan \& Smadi (2015) examined the difficulties that Jordanian EFL university students face in translating English idioms into Arabic. Ninety M.A translation students were asked to translate sixteen idioms. The findings showed that M.A students have difficulty in translating opaque and semi- opaque idioms. Paraphrasing was used as a strategy to give the meaning of these idioms. The researcher concluded that students demonstrated problems in rendering English idioms into their Arabic cultural equivalents; this is due mainly to their poor pragmatic competence in the target language (English).

Furthermore, Bani-younes (2015) investigated the problems that face students in translating collocations. In order to observe these problems, a questionnaire was given out to 40 MA students majoring in English Language. The findings showed that participants faced several cultural and sociolinguistic problems, such as the word order within the same collocation, the linguistic issues related to religious words, and the availability of acceptable equivalents in the target language. The findings also revealed that participants had not adequate proficiency in collocations

Finally, Yousefi (2017) focused on translation quality assessment, especially addressing the problems in translating the religious texts. In order to achieve the aim of the study, the researcher chose Waddington's model for evaluating the quality of translations; to find if the quality of translations of Islamic texts which were translated by Muslim translators were higher than those which were translated by non-Muslims. The study concluded that there was no relation between the religious beliefs of translators and the quality of translations.

Looking back into these studies, the researchers noted that most of these studies are devoted to examine either 
the students' ability in translating idiomatic expressions from English into Arabic (e.g., Ali, Al-Rushaidi, \& Mohammed, 2017; Alrishan \& Smadi, 2015; SajidJuma'a, 2014), or to explore the problems that face students in translating some Islamic expressions from Arabic into English (e.g., Dweik \& Suleiman, 2013; Khammyseh, 2015). However, little effort has been made to examine and little attention has been paid to investigate the semantics problems that Jarada University students in Jordan face in translating particular social-cultural concepts from the Arabic language to the English language. This study will therefore bridge this literature gap. The present study deals with functional equivalence of culture-specific expressions at the semantic level that have not been discussed widely in the previous studies such as social-cultural problems related to daily life expressions. Reviewing the above-mentioned studies helped the researchers to decide the methodology of the present study.

\section{Method}

In order to have homogenous group, the researchers selected 11 B.A translation students who have passed all the advanced translation courses and were familiar with translation of different types of texts specifically translation of culture-specific texts. The participants were between 21 to 23 years old. Each subject was given twenty culturespecific expressions to translate them from Arabic into English. These expressions were taken from volume two of the Jordanian Arabic novel "Mudun al-milh" (Cities of Salt) by Dr. A Munif. This novel was translated into English by Peter Theroux. He is an American writer and translator. He has translated several works of both historic and mainly contemporary fiction by Lebanese, Egyptian, Iraqi, and Jordanian. His translation of an Arabic work was nominated for PEN's annual prize for best translation of the year (Aboul-Ela 2014). Theroux's translation of Mudun al-milh helps the researchers to create a kind of comparison and contrast with the students' translations. This means that in order to identify any semantic problem and the reason beyond these problem, the participants' translations were analyzed and compared with Peter Theroux's translation (English version). The discrepancies between students' translation and Theroux's translation concerning the semantic errors will be presented in the next section.

\section{Analysis and Discussion}

This part of study deals with the semantic analysis of the B.A Translation student to find out if there are semantic deviations or any other semantic problems in their translations. Due to the limited space in this paper, few examples were used in the discussion. Out of twenty expressions translated by the students, only eight expressions were used in the analysis because the point of saturation was reached. This point is reached when no new ideas or categories are being generated from the data analysis (Banikalef et al. 2014). The table (1) below provides the original Arabic expression, which is taken from the novel called "Mudun al-milh" (Cities of Salt), and also it's translation by Theroux. The expressions are discussed individually below the table. Both translations are compared, and the translation strategy used has been identified.

Table 1. Translations of a culture-specific expressions

\begin{tabular}{|c|c|}
\hline Theroux's Translation & $\begin{array}{l}\text { The original Jordanian Arabic expressions } \\
\text { (Taken from "Mudun al-milh") }\end{array}$ \\
\hline O.K it's in God's hands". & على خيرة الله \\
\hline $\begin{array}{l}\text { Theroux neglected the translation of this expression. } \\
\text { We translate as "if God wills only good things occur" }\end{array}$ & ان شاء الله ما بصير الا الخير \\
\hline Money is his idol & دينه دنانيره \\
\hline $\begin{array}{l}\text { Theroux neglected the translation of this expression. } \\
\text { We translate as "God is our decision-maker" }\end{array}$ & الله يقسم الي فيه الخير \\
\hline He gets too strict & حنبلي اكثر من اللازم \\
\hline I swear I'll divorce my wife & 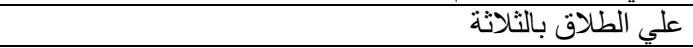 \\
\hline trust in God & وكل الله يا رجال \\
\hline I swear to fast for three days & نذرا علي اصوم ثلاثة ايام \\
\hline
\end{tabular}

1. "على خيرة الله، "was translated only by eleven students out of twenty. Some students opted for literal translation such as "on the good of God", "leave it to God", "God chooses the best". None of the students rendered this expression as "God blessing" which could be much more appropriate than any other form of translation as it combines both the denotative and the connotative meaning. The students were not able to grasp the intended meaning as it is a religious expression related to culture-bound expressions while Theroux provided a sort of functional translation which could be more acceptable or more appropriate " O.K it's in God's hands".

2. " once again, most of the students opted for "word-for-word" translation assuming that the direct meaning or the dictionary meaning would be sufficient whereas the expression is to be functionally rendered to capture the intended meaning. So, this expression has been translated as "By God's will, everything fine", "By God's will, everything will be O.K" and "everything will be O.K". the researchers believe that creating a functional equivalent to this expression is not an easy task. However, an accepted translation could be "if God 
wills only good things occur". Theroux did not translate this religious expression.

3. "وينه دنانيره", it is worth mentioning that a literal translation to this expression could be considered as an accepted translation and equivalent rendition " money is his religion" or "money is his idol" but none of the students provided this literal translations, they translated this as " he worships money", " he is a money worshipper"," all he cares only for money" and "money is his main concern". While Theroux rendered it as "Money is his idol" which is similar to one of the student's translation and it's an appropriate rendition.

4. "“الله بقسم السي فيه الخير", this expression has been wrongly misunderstood by most students assuming that the meaning of the word "يقسم" as "swear" or "oath" while the intended meaning of this word is that "it's in God's hand" i.e. God is our decision-maker. So, the incorrect translations resulted from misunderstanding of the denotative meaning of the Arabic word "يقسم" which means literally "decide" or "bestow". Also, Theroux neglected the translation of this expression.

5. " "حنبلي اكثر من اللانزم" the word "hanbaly" is related to an Islamic specialized person in the Islamic jurisprudence

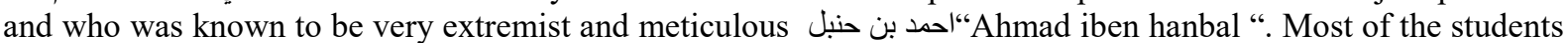
opted for transliteration as "Hanbali more than is needed" and some students paraphrased the concept as "tough believer" or "he is over religious". The researchers think that a good translation could be "he is too straight forward or meticulous". Theroux translated it as "He gets too strict" which is an appropriate translation.

6. “" this expression in Islam means that it's a sort of swearing, which indicates that I'm sure an action is going to happen or otherwise I'll divorce my wife irrevocably. The number three in this expression reveals the final state of divorce. Divorce in Islam has three steps or levels and once you reach the third step which is the final it becomes impossible to legally bring back your wife. Fortunately, being most of the students are Muslims, they provided excellent translation as "I swear to divorce my wife three times" or "I vow doing irrevocable divorce to my wife " and some of them opted simply for; "I swear" . Regarding the last translation, it seems that the hearer or the audience will get the idea that the speaker is God-believer. Theroux translated this expression literally as "I swear I'll divorce my wife" which is a good rendition but he deleted part of the translation which is number three indicating the final stage.

7. “و "وكل الله بي رجال" It's astonishing that most of the students provided accepted translations to this expression; " trust on God" ,"leave it to God" , "let God do it, man" and "depend on Allah". All these translations make sense and even the English-native speaker Peter Theroux attempted very similar translation as "trust in God".

8. "نزرا علي اصوم ثلاثة ايام", this expression has been translated by 10 students out of 11 students. Five students understood the word "نذرم" as a form of swearing and they rendered it as "swear" and "vow". "I swear to fast for three days", "I vow to fast for three days". Therefore, their translations were, to a very far extent, acceptable as they captured the intended meaning. The other five students understood the expression, not as a form of swearing, but as an informative statement that requires to be translated denotatively by giving the direct meaning of the expression which provided only partial meaning "I will fast for three days", "Three days a Muslim fasts when done wrong thing".

The descriptive analysis of the culture-specific expressions showed that students' mistranslations of most of the culture-specific expressions could be attributed or ascribed mainly to either misunderstanding the expressions or to the great cultural gaps. In addition, B.A students were not exposed to such cultural religious texts and their syllabus plan did not include such courses. The types of mistranslations could be categorized into three types. Firstly, an omission which means that some students provided partial meaning to the expression as a result of not knowing the total or the intended meaning like "نذر ا علي اصوم ثناثة ايام"which means that I swear to fast for three days, but the students attempted "I will fast for three days "omitting the word swear. Secondly, additions which mean that some students have added more than what it was required violating the assumption of translation which entails no loss no gain in translation regarding meaning like

” على خيرة الله" which means by God's will. The students attempted the following: "In God's we trust, and his arrangements are always the very best" violating the assumption above-mentioned by adding more information. Finally, the third type is a permutation which means that there should be a change in the world order according to the TLT. Most of the students have shown recurrent permutation in most of their translations because they have kept the same word order of the SLT. For example " " على خيرة الله "has been translated as "on the good of God" and " on God's willing" while the word order should be in accordance with the TLT.

The findings showed that most, if not all; specific cultural expressions are simply challenging to render or to understand for three principal reasons. Firstly, these expressions are specific to a given culture in terms of their linguistic structure, semantic denotation, and their socio-cognitive relevance. Secondly, most of the translation students do not have a sufficient explanation to cultural expressions; making it challenging to identify, recognize and translate to the target language. Thirdly, the students were unable to realize the context of these expressions. Some recent studies have confirmed these findings concluding that the students' inability to get the equivalent is one of the most serious difficulties in translation (Almubark et al. 2014; Cordaro et al. 2018; Outratov et al. 2013; Banikaelf \& Bataineh 2017) 


\section{Conclusion}

This study aimed to identify the semantics problems that Jadara University students in Jordan encounter in translating particular culture-specific expressions from the Arabic language to the English. Data analysis showed that the students faced several difficulties in translating culture-specific expressions from Arabic language into the English language, such as inability to get an appropriate correspondence and incapacity to apply the suitable methods in translating. Literal and deletion translation strategies were used frequently by the students in order to overcome the problem of rendering certain culture-specific expressions. Based on the data analysis, it was clear that students' unfamiliarity with the two cultures, inappropriate translation methods and approaches, were the main reasons for their weak translations. The study recommends that there is need for adding additional courses to educate the translators about culture-specific expressions. However, the main limitation of the present study is a small sample size, so the findings of this study cannot be generalized beyond the chosen participants. Finally, the findings of this study may motivate other researchers to do studies related to other issues in translating culturespecific expressions, including pragmatic issues.

\section{References}

Aboul-Ela, H., 2014. Challenging the Embargo: Arabic Literature in the US Market. Middle East Research and Information Project, 219(219), pp.42-44.

Ali, H., Al-Rushaidi, S. \& Mohammed, S., 2017. Translating Idiomatic Expressions from English into Arabic: Difficulties and Strategies. Arab World English Journal, 7(4), pp.187-201.

Almubark, A.A., Manan, A. \& Al-zubaid, K., 2014. The Hindrances in Translating Specific Cultural Concepts from Arabic into English. Journal Of Humanities And Social Science, 19(3), pp.166-173.

Alrishan, A. \& Smadi, O., 2015. Difficulties EFL Jordanian University Students Encounter in Translating English Idioms into Arabic. Journal of Education and Practice, 6(10), pp.124-134.

Bahaa-eddin, A.H., 2011. Literary translation: Aspects of pragmatic meaning, Newcastle upon Tyne: Cambridge Scholars Publishing.

Bani-younes, M.A., 2015. Cultural and Sociolinguistic Issues in English-Arabic Translation of Collocations. Studies in Literature and Language, 10(6), pp.53-58.

Banikaelf, A. \& Bataineh, K.B., 2017. A Sociolinguistic Study of Speech Act Realization Patterns in Jordanians ' Facebook Status Updates. International Journal of Linguistics, 9(3), pp.264-283.

Banikalef, A., Marlyna, M. \& Ashinida, A., 2014. Linguistic Analysis of Humor in Jordanian Arabic among Young Jordanians Facebookers. AWEJ, 5(3), pp.304-318.

Belloc, H., 1959. On Transilation. The Bible Translator, 10(2), pp.83-100.

Cordaro, D.T. et al., 2018. Universals and cultural variations in 22 emotional expressions across five cultures. Emotion, 18(1), p.75.

Dweik, B.S. \& Suleiman, M., 2013. Problems Encountered in Translating Cultural Expressions from Arabic into English. , 3(5).

Khammyseh, D., 2015. The Problems in Translating Islamic Expressions in Religious Occasions. Journal of Education and Practice, 6(35), pp.103-109.

Kohil, H., 2009. Investigating problems in translating English idiomatic phrasal verbs into Arabic. MA Thesis. Mentouri University of Constantine, Algeria.

Outratov, M., Palack, U. \& Anglistiky, K., 2013. Translating Culture Specific Concepts into English (from Czech promotional and information texts) (Bakalá ř ská práce). Filozofická fakulta Univerzity Palackého.

Panou, D., 2013. Equivalence in translation theories: A critical evaluation. Theory and Practice in Language Studies, 3(1), p.1.

SajidJuma'a, O., 2014. Translating Idiomatic Expressions from English into Arabic. Middle East University.

Sholihin, S., 2018. An Annotated Translation of "Techniques And Principles in Language Teaching"(Teaching Techniques in English as a Second Language. JJurnal Pendidikan Bahasa, 8(1), pp.29-36.

Shunnaq, A., 2012. Papers and Studies in Arabic Translation. Yarmouk University Publications, p.22.

Yousefi, S., 2017. Effect of Religious Beliefs on Quality of Translation. International Journal of Comparative Literature \& Translation Studies, 5(2), pp.32-38. 